\title{
A Neuro-Fuzzy Case Based Reasoning Framework for Detecting Lassa Fever Based on Observed Symptoms
}

\section{Samuel Ekene Nnebe*, Nora Augusta Ozemoya Okoh, Adetokunbo Mac Gregor John-Otumu, Emmanuel Osaze Oshoiribhor}

Department of Computer Science, Ambrose Alli University, Ekpoma, Nigeria

\section{Email address:}

nnebese@aauekpoma.edu.ng (S. E. Nnebe), augustaokoh@gmail.com (N. A. O. Okoh), macgregor.otumu@gmail.com (A. M. G. John-Otumu),emmaoshor2001@gmail.com (E. O. Oshoiribhor)

${ }^{*}$ Corresponding author

\section{To cite this article:}

Samuel Ekene Nnebe, Nora Augusta Ozemoya Okoh, Adetokunbo Mac Gregor John-Otumu, Emmanuel Osaze Oshoiribhor. A Neuro-Fuzzy Case Based Reasoning Framework for Detecting Lassa Fever Based on Observed Symptoms. American Journal of Artificial Intelligence. Vol. 3, No. 1, 2019, pp. 9-16. doi: 10.11648/j.ajai.20190301.12

Received: June 16, 2019; Accepted: July 13, 2019; Published: August 13, 2019

\begin{abstract}
Lassa fever is an acute viral haemorrhagic fever that is awfully infectious through infected rodents in the mastomysnatalensis species that are complex reservoirs capable of excreting the virus through their urine, saliva, excreta and other body fluids to man. The virus is a single stranded RNA virus belonging to the arenaviridae family. It presents no definite signs or symptoms and clinical analysis is often problematic especially at the early onset of the disease. Accurate diagnosis requires highly specialized laboratories, which are expensive and not readily available to the entire populace. Early diagnosis and treatment of Lassa fever is very vital for survival. In this study, we identified that fuzzy logic and rulebased techniques are the only artificial intelligence supported approach that has been used to develop an expert system for diagnosing the dreaded Lassa fever as an alternative to laboratory methodology. It is noted that rule-based is not an efficient technique in the designing expert systems based on its shortcomings such as opaque relations between rules, ineffective search strategy, and its inability to learn; while the fuzzy based technique does not also support the ability to learn but good in areas such as knowledge representation, uncertainty tolerance, imprecision tolerance, and explanation ability. Based on these information gathered, the authors decided to design a hybridized intelligent framework driven by the integration of Neural Network (NN), Fuzzy logic (FL) and Case Based Reasoning (CBR) based on their individual strengths put together in order to proffer a quick and reliable diagnosis for Lassa fever infection using observed clinical symptoms that could aid medical practitioners in decision making.
\end{abstract}

Keywords: Intelligence, Hybrid Model, Neuro-fuzzy CBR, Expert System, Lassa Fever

\section{Introduction}

Expert Systems (ES) uses human knowledge to solve problems which could normally require human intelligence. These ES represent the expertise knowledge as data or rules within the computer. These rules and data can be called upon when needed to solve problems. There are so much knowledge embedded in books and manuals, this knowledge cannot be useful if they are not read and interpreted by humans. Majority of ES are developed through specialized software called shells.

An Expert System shell is a software development environment containing the basic components for building expert system. It does not contain knowledge experts in a particular area. Thus, the shell-based approaches for building a system which is focused mainly on the system components but little on the user interface, making shellbased systems very suitable for users with programming skills [1].

Traditional rule-based expert system have been used over the time past to design expert systems for diagnosing medical conditions such as malaria fever, typhoid fever, leukemia, cerebral palsy, viral infection, influenza [2-7].

Lassa virus is zoonotic and infected rodents in the mastomysnatalensis species are complex reservoirs capable 
of excreting the virus through urine, saliva, excreta and other body fluids to man [8].

Lassa fever virus is a single stranded RNA virus belonging to the arenaviridae family [8]. Lassa fever is an acute viral haemorrhagic fever that is awfully infectious [9]. Lassa fever occurs very frequently in different parts of Nigeria and affects approximately 100,000-500,000 persons per year in West Africa [10]. The fever was first exposed and reported in a town called Lassa in Borno State, Nigeria.

Lassa fever is characterized by symptoms like involuntary impulse to vomit, abnormal and frequent stooling, abdominal pain, sore throat, liver enlargement, inflamation of the membranous sac enclosing the heart, low blood pressure, fast heart rate, cough, chest pain, shortest of breath, severe headache, hearing loss, and body temperature above $38^{\circ} \mathrm{C}$ [11-12].

Lassa fever presents no definite signs; clinical analysis is often problematic especially at the early onset of disease. Accurate diagnosis therefore can be assisted with differential laboratory testing, clinical manifestations, epidemiological findings since definitive diagnosis requires investigations available only in highly specialized laboratories [13] which could be very expensive. Early diagnosis and treatment of Lassa fever is very vital for survival.

Rule-based and fuzzy logic are the only artificial intelligence based approach that has been used to design and implement an expert system for diagnosing the dreaded Lassa fever [14-15] due to the challenges involved in the cost of investigation as recognized by [13].

However, but the rule-based and the fuzzy logic have their own peculiar issues in using the techniques to build an efficient expert system for medical diagnosis. The rule-based systems have problems contending with issues like opaque relations between rules, ineffective search strategy, imprecision tolerance, adaptability, knowledge discovery and its inability to learn; while Fuzzy Logic (FL) based technique also have issues with its inability to learn but good in areas such as knowledge representation, uncertainty tolerance, imprecision tolerance, and explanation ability.

Intelligent hybrid system is the integration of different artificial intelligence based techniques in building an expert model. Neural Networks (NN) and Fuzzy Logic (FL) are normal corresponding techniques in building intelligent hybrid systems but integrating a third technique like Case Based Reasoning (CBR) to a Neuro-fuzzy model to form a Neuro-fuzzy CBR framework will make the knowledge base stronger for a more efficient result.
A neural network (NN) is a type of information processing unit, whose architecture is stirred by biological neural systems. It consists of three major layers, namely, the input layer, the hidden layer and the output layer (See Figure 1). The input is applied to the first layer (input), and the signals propagate through the middle (hidden) layer (s) to the output layer, which produces the result of the process. NN is a lowlevel computational structure that does well while dealing with raw data and it is very good in areas like learning, maintainability, knowledge recovery, adaptability, uncertainty tolerance, and imprecision tolerance [18].

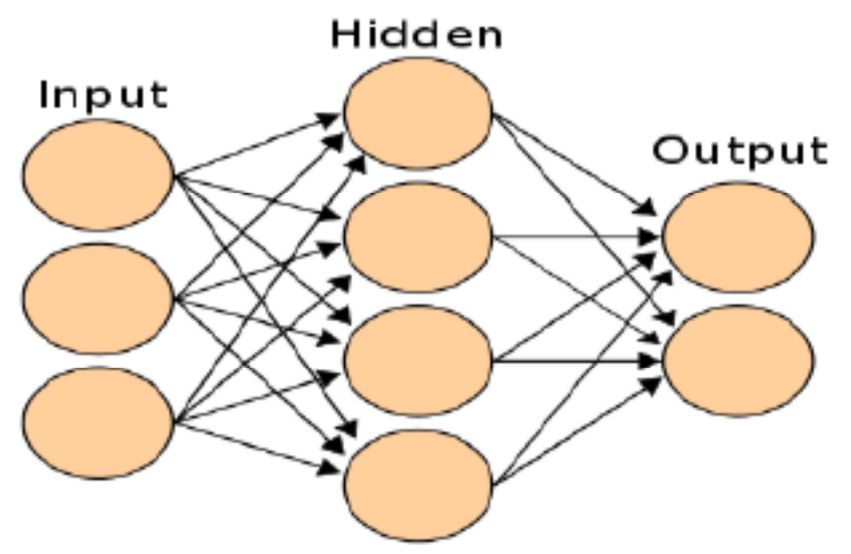

Figure 1. A Simple Artificial Neural Network Structure [27].

Fuzzy logic (FL) deals with reasoning on a higher level using linguistic information acquired from key domain expert, while Case Based Reasoning (CBR) reasons using analogy to represents knowledge; but rather poor in logic or rules like fuzzy and artificial neural network.

As a follow up from above; the researchers decided to integrate the individual (AI) based techniques; Fuzzy Logic (FL), Case Based Reasoning (CBR), alongside Neural Network (NN) in designing a hybridized framework based on their individual strength put together in order to proffer a quick and reliable diagnosis of the dreaded Lassa fever using observed clinical symptoms.

\section{Literature Review}

In this section, we reviewed only related research work done on hybrid systems for medical diagnosis in a tabular form.

Table 1. Summary of the Hybrid models reviewed.

\begin{tabular}{|c|c|c|c|c|}
\hline No & Type of Ailment Diagnosed & Techniques used & Findings/Results & Comments \\
\hline 1. & Hypotension [16]. & Neuro-fuzzy & $\begin{array}{l}\text { The system is seen to be self-learning, } \\
\text { adaptive and is able to handle the } \\
\text { uncertainties. }\end{array}$ & $\begin{array}{l}\text { The neuro-fuzzy model was developed using } \\
\text { Microsoft Access and Microsoft Visual Basic. } \\
\text { Neuro-solution and Crystal report were also } \\
\text { used in the neural network analysis and } \\
\text { graphical representations. }\end{array}$ \\
\hline 2. & Leukemia [17]. & Neuro-fuzzy & $\begin{array}{l}\text { The output of the proposed system was } \\
\text { structured into three clusters (With } \\
\text { Leukemia, Might be Leukemia, Not } \\
\text { Leukemia). }\end{array}$ & $\begin{array}{l}\text { The neuro-fuzzy model was developed using } \\
\text { Microsoft Access and Microsoft Visual Basic. } \\
\text { Neuro-solution and Crystal report were also } \\
\text { used in the neural network analysis and }\end{array}$ \\
\hline
\end{tabular}




\begin{tabular}{|c|c|c|c|c|}
\hline No & Type of Ailment Diagnosed & Techniques used & Findings/Results & Comments \\
\hline & & & & graphical representations. \\
\hline 3. & Lung Disease [18]. & Neuro-fuzzy & $\begin{array}{l}\text { The proposed system achieved a } \\
\text { sensitivity, specificity and accuracy of } \\
100 \%, 75 \% \text { and } 95 \% \text { respectively. }\end{array}$ & $\begin{array}{l}\text { The experiment revealed that the performance } \\
\text { of the proposed system was comparable with } \\
\text { other standard measures. }\end{array}$ \\
\hline 4. & Breast Cancer [19]. & $\begin{array}{l}\text { Threshold Neuro } \\
\text { Fuzzy }\end{array}$ & $\begin{array}{l}\text { The system used a wide range of } \\
\text { BIRADS classification schemes to } \\
\text { enhance the level diagnosis accuracy. }\end{array}$ & $\begin{array}{l}\text { The proposed system could assist physicians, } \\
\text { radiologist and others in clinical diagnosis. }\end{array}$ \\
\hline 5. & Tuberculosis [20]. & $\begin{array}{l}\text { Neuro-fuzzy } \\
\text { approach }\end{array}$ & $\begin{array}{l}\text { The system used eleven input variables } \\
\text { as symptoms and a rule-base that consist } \\
\text { of about } 120 \text { rules to determine the } \\
\text { output parameter }\end{array}$ & The system was simulated using MATLAB 7.0 \\
\hline 6. & Tuberculosis [21]. & $\begin{array}{l}\text { Adaptive neuro- } \\
\text { fuzzy } \\
\text { methodology }\end{array}$ & $\begin{array}{l}\text { The system was able to categorize the } \\
\text { severity level as mild, moderate, severe } \\
\text { and very severe. }\end{array}$ & The system was simulated using MATLAB 7.0 \\
\hline 7. & Thyroid diseases [22]. & $\begin{array}{l}\text { Neuro-fuzzy } \\
\text { model }\end{array}$ & $\begin{array}{l}\text { The system could classify into } 3 \\
\text { categories: normal, hyper and hypo. }\end{array}$ & $\begin{array}{l}\text { The dataset were pre-processed using } \\
\text { Microsoft Excel to organize and classify the } \\
\text { dataset values before being used in the expert } \\
\text { system. Back propagation and fuzzy logic were } \\
\text { used in the training. }\end{array}$ \\
\hline 8. & Heart disease [23]. & Neuro-fuzzy & $\begin{array}{l}\text { The model classification system is seen } \\
\text { to be effective in the heart disease } \\
\text { diagnosis. }\end{array}$ & $\begin{array}{l}\text { The system incorporated the human-like } \\
\text { reasoning style of fuzzy systems through the } \\
\text { use of fuzzy sets and a linguistic model } \\
\text { consisting of IF-THEN fuzzy rules. }\end{array}$ \\
\hline 9. & Multiple Sclerosis [24]. & Neuro-fuzzy & $\begin{array}{l}\text { The simulated results showed that the } \\
\text { proposed system has about } 96 \% \\
\text { accuracy. }\end{array}$ & The system was implemented using MATLAB. \\
\hline 10. & $\begin{array}{l}\text { Ebola Haemorrhagic Fever } \\
\text { (EHF) [25]. }\end{array}$ & Neuro-fuzzy & $\begin{array}{l}\text { Result revealed that about } 9 \text { clinical } \\
\text { symptoms and } 29 \text { clinical signs and } \\
\text { symptoms further classified into } 5 \text { Tiers } \\
\text { were used }\end{array}$ & $\begin{array}{l}\text { MATLAB and Fuzzy Logic tool box were used } \\
\text { to simulate the entire process. }\end{array}$ \\
\hline 11. & $\begin{array}{l}\text { Classification of cells as } \\
\text { cancerous or non-cancerous } \\
{[26] .}\end{array}$ & Neuro-fuzzy & $\begin{array}{l}\text { Results showed about } 70 \% \text { accuracy and } \\
89 \% \text { precision. }\end{array}$ & $\begin{array}{l}\text { ANN Back propagation algorithm was used in } \\
\text { training the system, while the cancerous cells } \\
\text { were passed into the fuzzy inference engine for } \\
\text { classification. }\end{array}$ \\
\hline 12. & Monkey pox diseases [27]. & $\begin{array}{l}\text { Neuro-fuzzy } \\
\text { model }\end{array}$ & $\begin{array}{l}\text { A dataset of } 18 \text { symptoms were captured } \\
\text { to form the rule-base, and the output } \\
\text { was designed to result classified into } \\
\text { mild, moderate, severe and very severe. }\end{array}$ & $\begin{array}{l}\text { The proposed model was simulated using } \\
\text { Matrix Laboratory (MATLAB) }\end{array}$ \\
\hline 13. & Disease diagnosis [28]. & $\begin{array}{l}\text { Neuro-fuzzy } \\
\text { model }\end{array}$ & $\begin{array}{l}\text { The system is fast and perfect for } \\
\text { disease diagnosis. }\end{array}$ & $\begin{array}{l}\text { The system is recommended for usage by both } \\
\text { patients and doctors. }\end{array}$ \\
\hline
\end{tabular}

\section{Methodology}

This section shows the proposed Neuro-fuzzy Case Based Reasoning framework and system architecture for the detection of Lassa fever. It also shows the various symptoms associated with Lassa fever, and explains the various algorithms that will be used in the framework.

\subsection{Proposed Neuro-Fuzzy CBR Framework}

The integration of the strengths of Case Based Reasoning (CBR), Neural Network (NN) and Fuzzy Logic (FL) forms the robust Neuro-fuzzy CBR framework.

Figure 2 depicts our proposed Neuro-fuzzy case based reasoning framework for diagnosing Lassa fever. The framework uses three (3) different techniques to achieve its desired objective.

(a) Case Based Reasoning (CBR)

$\mathrm{CBR}$ relies on the process of reasoning by analogy. To solve a new problem, the system does the following:

(i) Here is a new problem. How can we solve it?

(ii) Compare the new problem to all the problems we solved in the past. Which one does it resemble the most?

(iii) Reuse the solution of the most similar past problem by adapting it to get a solution for the new problem.

(iv) Finally, file away the new problem and its solution for reference in solving future problems. 


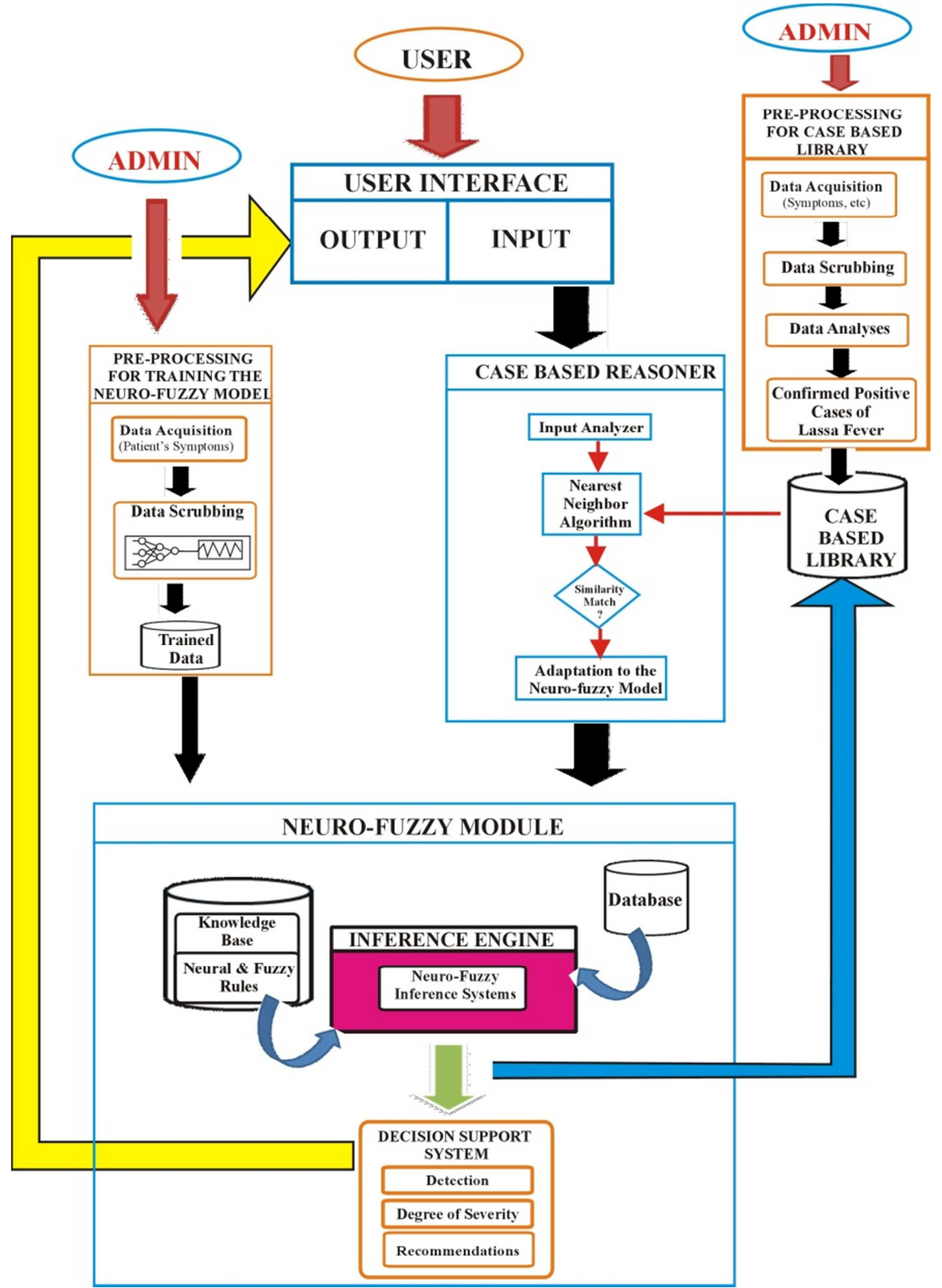

Figure 2. Proposed Neuro-fuzzy Case Based Reasoning Framework for Lassa fever Diagnosis.

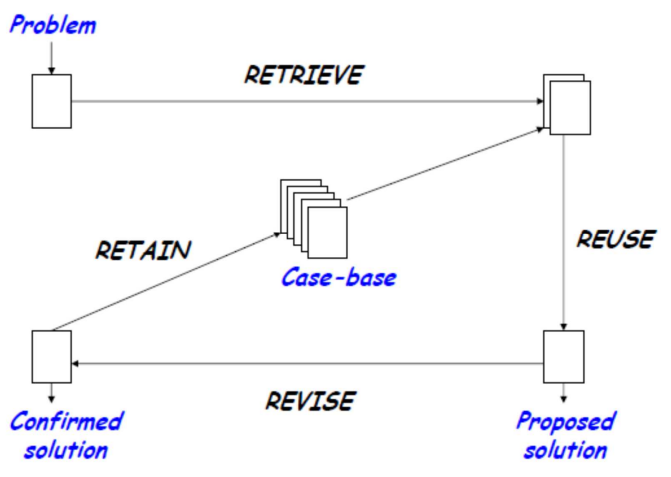

Figure 3. Structure of a case based system.
In the proposed neuro-fuzzy CBR framework, we used the Euclidean Distance as a Nearest Neighbor Algorithm in the CBR module. In calculating the distance between two points in an n-dimensional space the Euclidean distance formula becomes a very good choice.

The formula is Euclidean distance:

$$
\left.\sqrt{\left[\left(a_{1}-a_{2}\right)^{2}+\left(b_{1}-b_{2}\right)^{2}+\left(c_{1}-c_{2}\right)^{2}+\cdots+\left(z_{1}-z_{2}\right)^{2}\right.}\right]
$$

To find out whether the specimen case is more similar to case 1 , case 2 up to the $n^{\text {th }}$ case in the case library, the system will simply calculate the two distances, and pick the smallest of them to use its solution for the new case through its adaptation to the next phase which is neural network. 


\section{(b) Neural Network (NN)}

The neural network receives possible signs and symptoms from a user into its input layer for a new case either through the case based reasoning module's adaptation phase using found case solution to solve for the new case i. e. after searching through all the records (cases) in the case library and computation for a measure of similarity has been determined using Euclidean distance or no similar record found, then control is handled over to the neural network for computation thereafter.

Thus the activation function of the neuron can be represented as

$$
X=\sum_{i=1}^{n} x_{i} * w_{j}
$$

Where $\mathrm{X}=$ is the net weighted input to the neuron

$\mathrm{x}_{\mathrm{i}}$ and $\mathrm{w}_{\mathrm{j}}$ are the value of input $\mathrm{i}$ and its weight $\mathrm{j}$ respectively, and $\mathrm{n}$ is the number of neuron inputs, $\mathrm{Y}$ is the output of the neuron.

$$
Y= \begin{cases}+1, & \text { if } x>\theta \\ -1, \text { if } x<\theta\end{cases}
$$

Here, theta $(\theta)$ is the defined as our threshold value or baseline given to determine the presence absence of a proven case. (c) Fuzzy Logic (FL)

We activate the fuzzy logic to classify the final output from the neural network for a suspected case of Lassa fever into its degree of severity based on the initial twenty-nine clinical symptoms recognized.

$$
\mathrm{Y}=\sum_{i=1}^{n} L_{3}(x i)
$$

Lastly, employ Eq. (5) to classify the crisps numeric values in Eq. (4) as the system's final output, which represents the patient's diagnostic result.

$$
\text { Output }=\left\{\begin{array}{cc}
\text { Mild } & 0.6 \leq Y<0.7 \\
\text { Moderate } & 0.7 \leq Y<0.8 \\
\text { Severe } & 0.8 \leq Y \leq 1.0
\end{array}\right.
$$

\subsection{The Neuro-Fuzzy CBR System Architecture}

The analysis and diagnosis of Lassa fever will provide a self-learning and adaptive system that is able to handle uncertain and imprecise data as if it was a human expert.

Figure 4 depicts the Neuro-fuzzy CBR architecture that performs the processes in order to detect a suspected case of Lassa fever and also further classifies the suspected case into degree of severity.

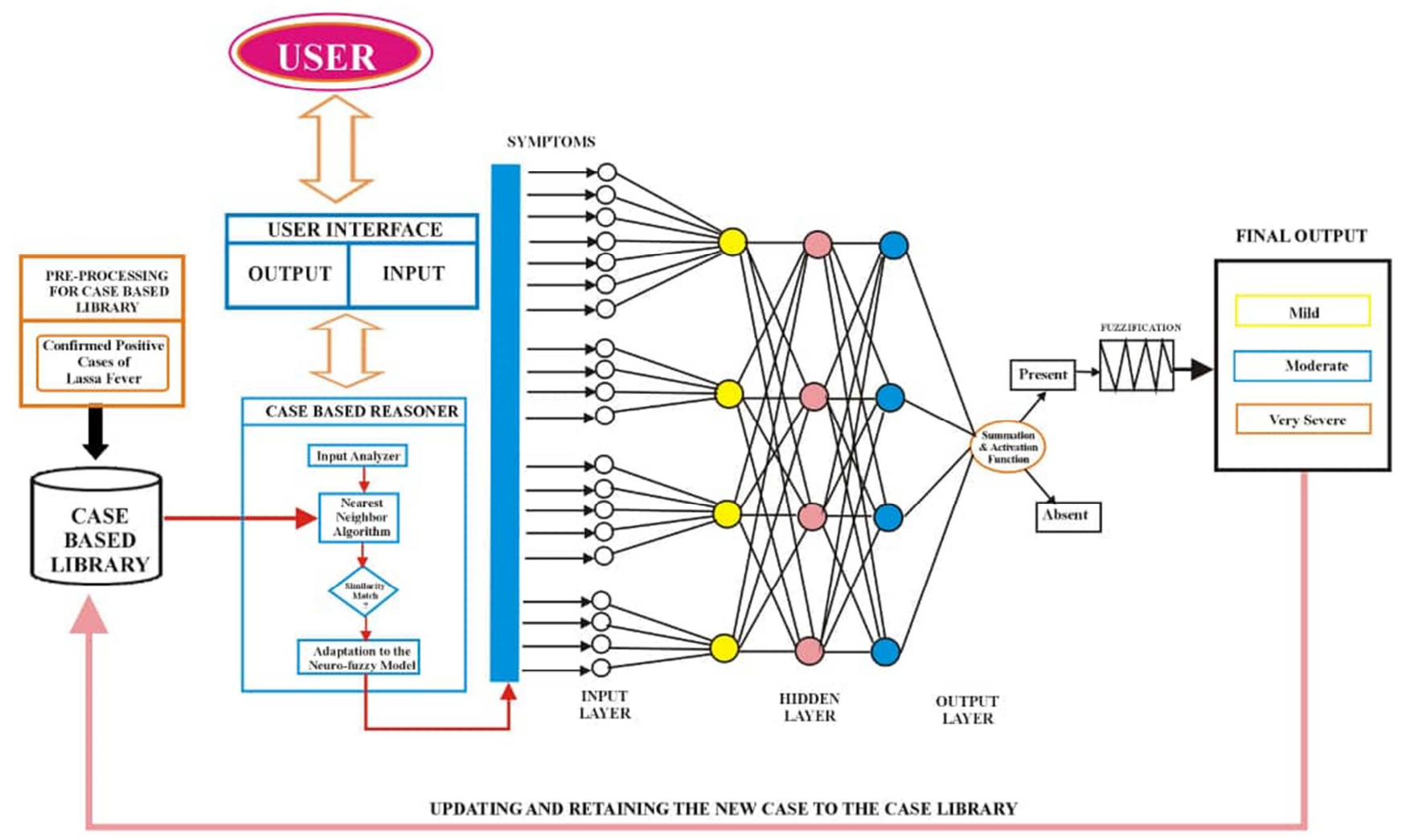

Figure 4. System architecture of the Neuro-Fuzzy CBR Model.

\subsection{The Neuro-Fuzzy CBR Algorithm}

Step 1: Input personal observed symptoms as a new case. Step 2: Submit the input symptoms for diagnoses.

Step 3: Activate the Euclidean distance as a Nearest
Neighbor Algorithm.

Step 4: Compare the new case with all the sets of past confirmed positive and negative Cases stored in the Case Based Library for a measure of similarity match using the Euclidean distance model. 
$\sqrt{\left[\left(a_{1}-a_{2}\right)^{2}+\left(b_{1}-b_{2}\right)^{2}+\left(c_{1}-c_{2}\right)^{2}+\cdots+\left(z_{1}-z_{2}\right)^{2}\right]}$

Step 5: Which past case does the new case resemble the most?

Step 6: IF a measure of similarity match is found Continue processing Else Goto Step 10.

Step 8 Re-use that solution of the most similar past Case.

Step 9: Adapt the past Case solution to get a solution for the new Case using the Neural Network Model.

Step 10: Activate the Neural Network (NN) Model.

Step 11: Compute for $X=\sum_{i=1}^{n} x_{i} * w_{j}$

Step 12: Compute for
$Y=\left\{\begin{aligned} \text { Positive case of Lassa fever detected, } & \text { if } x>\theta \\ \text { Negative case of Lassa fever detected, } & \text { if } x<\theta\end{aligned}\right.$

Step 13: Activation of the Fuzzy Logic (FL) Model

Step 14: Compute for degree of severity $\mathrm{Y}=\sum_{i=1}^{n} L_{3}(x i)$

Step 15: Generate classified

$$
\text { Output }=\left\{\begin{array}{cc}
\text { Mild } & 0.6 \leq Y<0.7 \\
\text { Moderate } & 0.7 \leq Y<0.8 \\
\text { Severe } & 0.8 \leq Y \leq 1.0
\end{array}\right.
$$

Step 16: Retain the new Case and its solution into the Case Based Library for reference purpose in solving future Cases.

Step 17: Update the Case Based Library.

Table 2. Symptoms of Lassa fever.

\begin{tabular}{|c|c|}
\hline Symptoms & Code \\
\hline Involuntary impulse to vomit & P 01 \\
\hline Abnormal and frequent stooling & $\mathrm{P} 02$ \\
\hline Abdominal pain & P 03 \\
\hline Infrequent and difficulty in stooling & P 04 \\
\hline Difficulty swallowing & P 05 \\
\hline Liver enlargement & P 06 \\
\hline Yellow discoloration of the skin, whites of the eyes, etc & P 07 \\
\hline Inflammation of the membranous sac enclosing the heart & P 08 \\
\hline High blood pressure & P 09 \\
\hline Low blood pressure & P 10 \\
\hline Fast heart rate & P 11 \\
\hline Cough & P 12 \\
\hline Chest pain & P 13 \\
\hline Shortness of breath & P 14 \\
\hline Sore throat & P 15 \\
\hline Abnormal sleepiness or sleeping sickness & P 16 \\
\hline Severe headache, and stiffness of the neck or back muscles & P 17 \\
\hline Hearing loss involving one side only or double sides & P 18 \\
\hline Loss of attention or sleepiness or an outburst of great uncontrollable laughter with loss of consciousness & P 19 \\
\hline Body temperature $>37^{\circ} \mathrm{C}$ & P 20 \\
\hline Dehydration & P 21 \\
\hline General body weakness & P 22 \\
\hline Abnormal large amount of protein in the urine & P 23 \\
\hline Swollen face & P 24 \\
\hline Mucosal bleeding (Mouth, Nose, and Eyes) & Р 25 \\
\hline Abnormal decrease in the number of blood platelets & Р 26 \\
\hline Internal bleeding & P 27 \\
\hline Frequent backache & P 28 \\
\hline Confusion or disorientation & Р 29 \\
\hline
\end{tabular}

Table 2 shows about twenty-nine signs / symptoms of Lassa fever gathered through journals, conference proceedings, manuals and interview sessions with medical practitioners and medical laboratory scientist in the domain area.

\section{Results and Discussion}

The study shows a hybrid framework designed for detecting a suspected case of Lassa fever using a combination of three different techniques put together that would offer a more effective and efficient system of medical diagnosis for improved system results, accuracy of detection rates and minimization of false alarm rates as compared to single approaches like the rule-based model and fuzzy model used for diagnosing Lassa fever by other research scholars [14-15].
Our proposed intelligent Neuro-fuzzy CBR model is seen to have a stronger and more intelligent knowledge base in terms of learning ability, knowledge representation, imprecision tolerance, uncertainty tolerance, explanation ability, maintainability, knowledge recovery, and adaptability when compared to models developed by [14-15].

\section{Conclusion}

The use of intelligent hybrid techniques in medical diagnosis cannot be overemphasized as they have seriously added value in medical diagnosis. This novel study demonstrated how an integration of different techniques can assist to a very large extent in the diagnosis of Lassa fever.

The Neuro-fuzzy CBR framework employed three main 
algorithms as part of its design for complete diagnosis: Nearest neighbor algorithm, back propagation algorithm, and fuzzy clustering algorithm.

Our Neuro-fuzzy CBR framework is designed as an efficient means to diagnose a suspected case of Lassa fever based on the twenty-nine observed symptoms captured. The proposed model designed is recommended for adaptation into other chronic medical conditions such as HIV/AIDS, INFLUENZA, EBOLA, etc in order to enhance the fast and accurate processing of clinical decisions.

In future, researchers should consider translating our architectural framework into a software prototype using a suitable programming language in order to evaluate the accuracy level of the model with other models.

Moreso, other hybrid approach and machine learning techniques should also be investigated to effectively tackle this Lassa fever menace.

\section{Acknowledgements}

The authors wish to express their gratitude to Dr. Vincent Aiwuyo (Medical Doctor) and Mr. Felix Aitufe (Principal Medical Lab Scientist) of Ambrose Alli University Health Centre, Ekpoma, Edo State for sharing their time and knowledge on issues pertaining Lassa fever.

The authors are also very grateful to Dr. Ephraim OgbawiEmovon (Director, Institute of Lassa Fever Research and Control, Irrua Specialist Teaching Hospital, Edo State, Nigeria) and some his key laboratory scientist at the research institute, namely; Dr. Donatus E. Adomeh (Ph. D, DDMLS), Mr. Aire Chris, FMLSCN, and Mr. Ikponmwosa Odia, ADMLS (Lab Manager) for also sharing their very precious time, indebt knowledge on Lassa fever trend of infection, detailed clinical signs and symptoms, variety of biomedical equipment for diagnoses available, control measures, degree of severity classification, possible treatment plan for suspected cases, and finally some of their published work on the trend of Lassa fever.

\section{References}

[1] K. Sanjay and P. Rajkishore (2015), Importance of Expert System Shell in Development of Expert System, International Journal of Innovative Research and Development, 4 (3): 128133.

[2] S. A. Fatumo, E. Adetiba, and J. O. Onaolapo (2013). Implementation of XpertMalTyph: An Expert System for Medical Diagnosis of the Complications of Malaria and Typhoid, IOSR Journal of Computer Engineering, 8 (5): 34-40.

[3] J. C. Obi and A. A. Imianvan (2011). Interactive Neuro-Fuzzy Expert System for Diagnosis of Leukemia, Global Journal of Computer Science and Technology, 11 (12): 42-50.

[4] S. Tunmibi, O. Adeniji, A. Aregbesola, and D. Ayodeji (2013). A Rule Based Expert System for Diagnosis of Fever, International Journal of Advanced Research, 1 (7): 343-348.

[5] M. Patel, A. Patel, and P. Virparia (2013), Rule Based Expert
System for Viral Infection Diagnosis, International Journal of Advanced Research in Computer Science and Software Engineering, 3 (5).

[6] M. S. Hossain, M. S. Khalid, S. Akter, and S. Dey (2014). A belief rule-based expert system to diagnose influenza, In proceedings of Strategic Technology $9^{\text {th }}$ International Forum 2014 IEEE.

[7] R. H. Komal and S. G. Vijay (2014), Rule-Based Expert System for the Diagnosis of Memory Loss Diseases, International Journal of Innovative Science, Engineering \& Technology, 1 (3).

[8] K. C. Eze, T. A. T. Salami, I. C. Eze, A. E. Pogoson, N. Omordia and M. O. Ugochukwu (2010), High Lassa fever activity in Northern part of Edo state, Nigeria: Re-analysis of confirmatory test results, Afr Journal of Health Science, 17: 52-56.

[9] M. D. Bowen, P. E. Rollin, T. G. Ksiazek, H. L. Hustad, D. G. Bausch, and A. H. Demby (2000), Genetic diversity among Lassa virus strains. Journal of Virol, 74 (15): 6992-7004.

[10] O. Ogbu, E. Ajuluchukwu, and C. J. Uneke (2007), Lassa fever in West Africa sub-region: An Overview, Journal of Vect Borne Dis. 44 (1): 1-11.

[11] Centre for Disease Control and Prevention. Lassa fever fact sheet. 2014. Available: http://www.cdc. gov/ncidod/dvrd/spb/mnpages/dispages/factsheets/lassa fever _fact_sheet. pdf. Accessed January 2016. Google Scholar

[12] World Health Organisation. World Health Organisation fact sheet on Lassa fever. 2015; 10 (11). Google Scholar.

[13] A. I. Nasir and M. F. Sani (2015), Outbreak, pathogen containment and laboratory investigation of Lassa fever in Nigeria: How prepared are we? International Journal of Tropical Disease and Health, 10 (1): 1-10.

[14] M. A. Hambali, A. A. Akinyemi, and J. D. Luka (2017). Expert System For Lassa Fever Diagnosis Using Rule Based Approach, Annals Computer Science Series, 15 (2): 68-74.

[15] R. O. Osaseri, E. A. Onibere, and A. R. Usiobiafo (2014). Fuzzy Expert Model for Diagnosis of Lassa fever, Journal of the Nigerian Association of Mathematical Physics, 27: 533540 .

[16] A. A. Imianvan and J. C. Obi (2012). Cognitive Neuro-Fuzzy System for Hypotension Control, Computer Engineering and Intelligent Systems, 3 (6): 21-31.

[17] J. C. Obi and A. A. Imianvan (2011). Interactive Neuro-Fuzzy Expert System for Diagnosis of Leukemia, Global Journal of Computer Science and Technology, 11 (12): 42-50.

[18] T. Manikandan, N. Bharathi, M. Sathish, and V. Asokan (2017), Hybrid Neuro-Fuzzy System for Prediction of Lung Disease Based on the Observed Symptom Values, Journal of Chemical and Pharmaceutical Sciences, 8: 69-76.

[19] M. Nagarajasri and M. Padmavathamma (2013), Threshold Neuro Fuzzy Expert System for Diagnosis of Breast Cancer, International Journal of Computer Applications, 66 (8): 6-10.

[20] J. M. Gumpy, I. Goni, and M. (2018), Neuro-Fuzzy Approach for Diagnosing and Control of Tuberculosis. The International Journal of Computational Science, Information Technology and Control Engineering, 5 (1): 1-10. 
[21] Goni, I., Ngene, C. U., Manga, I., and Auwal, N., and Sunday, J. C. (2018), Intelligent System for Diagnosing Tuberculosis Using Adaptive Neuro-Fuzzy, Asian Journal of Research in Computer Science, 2 (1): 1-9.

[22] Oladele, T. M., Okonji, C. D., Adekanmi, A., and Abiola, F. F. (2018). Neuro-Fuzzy Expert System for Diagnosis of Thyroid Diseases, Annale Computer Science Series, 16 (2): 45-54.

[23] E. P. Ephzibah and V. Sundarapandian (2012). A Neuro Fuzzy Expert System for Heart Disease Diagnosis, Computer Science \& Engineering: An International Journal, 2 (1): 17-23.

[24] M. E. Shaabani, T. Banirostam, and A. Hedayati (2016), Implementation of Neuro Fuzzy System for Diagnosis of Multiple Sclerosis, International Journal of Computer Science and Network, 5 (1): 157-164.
[25] A. O. Egwali, and J. C. Obi (2015), An Adaptive Neuro-Fuzzy Inference System for Diagnosis of EHF, The Pacific Journal of Science and Technology, 16 (1): 251-261.

[26] A. Omotosho, A. E. Oluwatobi, and O. R. Oluwaseun, (2018). A Neuro-Fuzzy System for the Classification of Cells as Cancerous or Non-Cancerous, International Journal of Medical Research and Health Sciences, 7 (5): 155-166.

[27] J. J. Tom and N. P. Anebo (2018), A Neuro-Fuzzy Based Model for Diagnosis of Monkeypox Diseases, International Journal of Computer Science Trends and Technology, 6 (2): 143-153.

[28] S. Maskara, A. Kushwaha, and S. Bhardwaj (2018), Adaptive Neuro Fuzzy Expert System for Disease Diagnosis, International Journal of Innovations in Engineering and Technology, 10 (2): 121-123. 